\title{
Neuropathology and Neurochemistry of Nonmotor Symptoms in Parkinson's Disease
}

\author{
Isidro Ferrer \\ Institut de Neuropatologia, Servei Anatomia Patològica, IDIBELL-Hospital Universitari de Bellvitge, Universitat de Barcelona, \\ carrer Feixa LLarga sn, CIBERNED, 08907 Hospitalet de LLobregat, Spain \\ Correspondence should be addressed to Isidro Ferrer, 8082ifa@gmail.com
}

Received 11 October 2010; Accepted 16 December 2010

Academic Editor: Irena Rektorova

Copyright ( $\odot 2011$ Isidro Ferrer. This is an open access article distributed under the Creative Commons Attribution License, which permits unrestricted use, distribution, and reproduction in any medium, provided the original work is properly cited.

Parkinson disease (PD) is no longer considered a complex motor disorder characterized by Parkinsonism but rather a systemic disease with variegated non-motor deficits and neurological symptoms, including impaired olfaction, autonomic failure, cognitive impairment, and psychiatric symptoms. Many of these alterations appear before or in parallel with motor deficits and then worsen with disease progression. Although there is a close relation between motor symptoms and the presence of Lewy bodies (LBs) and neurites filled with abnormal $\alpha$-synuclein, other neurological alterations are independent of the amount of $\alpha$-synuclein inclusions in neurons and neurites, thereby indicating that different mechanisms probably converge in the degenerative process. Involvement of the cerebral cortex that may lead to altered behaviour and cognition are related to several convergent factors such as (a) abnormal $\alpha$-synuclein and other proteins at the synapses, rather than LBs and neurites, (b) impaired dopaminergic, noradrenergic, cholinergic and serotoninergic cortical innervation, and (c) altered neuronal function resulting from reduced energy production and increased energy demands. These alterations appear at early stages of the disease and may precede by years the appearance of cell loss and cortical atrophy.

\section{Introduction}

Parkinson disease (PD) is clinically characterized by a complex motor disorder known as parkinsonism and is manifested principally by resting tremor, slowness of initial movement, rigidity, and general postural instability. These symptoms are mainly due to the loss of dopaminergic neurons in the substantia nigra pars compacta, leading to reduced dopaminergic input to the striatum and accompanied by adaptive responses in the internal and external globus pallidus, subthalamus, thalamus and substantia nigra pars reticularis. Round, hyaline neuronal cytoplasmic inclusions called Lewy bodies (LBs) and enlarged aberrant neurites and threads are found in the Parkinsonian substantia nigra $[1,2]$. In addition to the substantia nigra, other nuclei are involved such as the locus ceruleus, reticular nuclei of the brain stem, and dorsal motor nucleus of the vagus, as well as the basal nucleus of Meynert, the amygdala and the CA2 area of the hippocampus. LBs and aberrant neurites are also found in these locations [1-7]. Similar lesions but extended to the cerebral neocortex are characteristic of a closelyrelated disease named Dementia with Lewy bodies (DLB) [8]. PD and DLB are therefore considered Lewy body diseases (LBDs). Neuropathology and clinical aspects of DLB have been revised in detail elsewhere $[9,10]$.

LBs and neurites are composed of aggregates of normal, misfolded and truncated proteins, and ubiquitin, all of which are stored in the cytoplasm as nondegraded byproducts of the degenerative process [11-14]. The main component of LBs and aberrant neurites is $\alpha$-synuclein which is abnormally phosphorylated, nitrated and oxidized, has an abnormal crystallographic structure and abnormal solubility, and is prone to the formation of aggregates and insoluble fibrils [15-23]. For this reason, LBDs are categorized as $\alpha$-synucleinopathies.

Mutations (A53T, A30P, E46K) in the $\alpha$-synuclein gene (SNCA; PARK1) are causative of autosomal dominant PD [24-26]. In addition, triplication or duplication of the $\alpha$ synuclein locus is associated with PD [27-30]. Together, these observations lay bare the crucial role of $\alpha$-synuclein 
in the pathogenesis of a percentage of familial cases of PD. Recent studies have shown that methylation of the human SNCA intron 1 reduces gene expression, and inhibition of DNA methylation activates SNCA expression. Methylation of $S N C A$ intron 1 is reduced in substantia nigra, putamen and cerebral cortex in $\mathrm{PD}$, suggesting activation of SNCA in PD [31]. $\alpha$-synuclein also appears to be regulated posttranscriptionally as two microRNAs, mir-7 and mir-153, which bind specifically to the $3^{\prime}$-untranslated region of $\alpha$ synuclein and downregulate its mRNA and protein levels [32]. The two microRNAs reduce endogenous expression of $\alpha$-synuclein $[32,33]$. Whether variation in the miRNA-433 binding site of fibroblast growth factor 20 confers risk for PD by overexpression of $\alpha$-synuclein [34] requires further validation.

Mutations in other genes are also the origin of familial and, in some cases, sporadic PD. These include parkin (PARK2) [35], DJ1 (PARK7) coding for Parkinson disease protein 7 [36], PINK1 (PARK6) coding for PTEN-induced putative kinase 1 [37], LRRK2 (PARK8) coding for leucinerich repeat kinase $2[38,39]$ and HTRA2 (PARK13) coding for HtrA serine peptidase 2: HtrA2 [40]. Another gene involved in familial PD is UCHL1 (PARK5) coding for ubiquitin carboxyl-terminal hydrolase L1 [41]. A strong association between galactocerebrosidase mutations and PD has recently been reported [42]. Additonal loci associated with autosomal or recessive PD have been described (see [43-45]). An important point is that not all familial cases with PD due to parkin and LRRK2 mutations have LBs, although all of them have predominant degeneration of the substantia nigra pars compacta (see [46], for review). Therefore, PD cases due to parkin and LRRK2 mutations without LBs cannot be considered as instances of LBD. Yet mutations in PINK1 are associated with LB pathology similar to that seen in sporadic PD [47].

\section{Stages of PD-Related Pathology}

Systematic study of cases with LB pathology has prompted a staging classification of PD based on the putative progression of LB pathology from the medulla oblongata (and olfactory bulb) to the midbrain, diencephalic nuclei, and neocortex [48-50]). Stage 1 is characterized by LBs and neurites in the dorsal IX/X motor nuclei and/or intermediate reticular zone; there is also myenteric plexus involvement. Stage 2 affects the medulla oblongata and pontine tegmentum and covers pathology of stage 1 plus lesions in the caudal raphe nuclei, gigantocellular reticular nucleus, and ceruleus-subceruleus complex; the olfactory bulb is also involved. Stage 3 refers to pathology of stage 2 plus midbrain lesions, particularly in the pars compacta of the substantia nigra. Stage 4 includes basal prosencephalon and mesocortex pathology (cortical involvement confined to the transentorhinal region and allocortex, and CA2 plexus) in addition to lesions in the midbrain, pons and medulla oblongata. Stage 5 extends to sensory association areas of the neocortex and prefrontal neocortex. Stage 6 includes, in addition, lesions in first order sensory association areas of the neocortex and premotor areas; occasionally there are also mild changes in primary sensory areas and the primary motor field.

Cases with Lewy pathology in the brain stem without clinical evidence of parkinsonism are considered premotor PD or incidental LBD $[1,2]$. Risk factor profiles in incidental LBD and PD are similar thus further supporting the idea that iLBD represents preclinical PD, arrested PD or a partial syndrome [51].

Furthermore, several atypical cases have been reported, the majority of them not following a clear gradient of Lewy body pathology from the medulla oblongata to the neocortex. LBs in the amygdala are predominant or even unique in some cases, most of them related with Alzheimer's disease and Down syndrome. For this reason, amygdalapredominant LB disease has been categorized as a distinct entity [52]. Finally, a few cases have been reported with predominant cortical LB pathology and discrete numbers of LBs in the brain stem $[53,54]$. Atypical cases constitute from five to ten percent of total LBD victims [55-58].

Cumulative clinical evidence reveals that olfactory dysfunction, dysautonomia, sleep fragmentation, rapid eye movement behaviour disorder, mood and anxiety disorders, and depression may precede parkinsonian symptoms in a number of patients with PD clinically characterized by parkinsonism [59-70]. Whether these clinical symptoms are associated with LBs in selected regions of the central, autonomous and peripheral nervous systems is a matter of study.

The neuropathological substrates of selected nonmotor symptoms in PD have been examined in previous reports [7] and will be reviewed in the following paragraphs.

\section{Loss of Olfaction and the Olfactory Bulb and Tract in PD}

$\alpha$-synuclein pathology affecting neurons and neurites occurs in the olfactory bulb and related olfactory nuclei at very early stages of cases with PD-related pathology [50, 71-75]. It also occurs in cases of $\mathrm{AD}$ with amygdala-predominant LB pathology [76]. Double-labelling immunohistochemical studies have shown that dopamine- and somatostninpositive cells are rarely affected, whereas mitral cells, calcium-binding protein- and substance-P-positive cells are vulnerable [77]. Olfactory bulb synucleinopathy has high specificity and sensitivity for Lewy body diseases, and it has been suggested that olfactory bulb biopsy might be considered to confirm diagnosis in PD [78], an indication not approved by others [79].

The number of intracytoplasmic and neuritic $\alpha$-synuclein inclusions in the olfactory bulb and tract is low in the majority of cases, thus suggesting that $\alpha$-synuclein aggregates as visualized in current histological preparations barely begin to explain the severity of olfactory decline. It may be hypothesized that as in other regions, olfactory alterations in $\mathrm{PD}$ are the result of more complicated settings resulting from several molecular deficits. Although no direct information is as yet available in PD, recent studies have yielded substantial data about the molecular pathology of the olfactory bulb. 
Despite the relatively high content of glucose-6-phosphate dehydrogenase (G6PD), NADPH-cytochrome P450 oxidoreductase, glutathione reductase (GR) and NADPH-diaphorase (NADPH-d) in the olfactory bulb of rodents [80], significant changes in carbonylation and nitration have been found in the olfactory bulbs of old mice [81]. Targets of oxidation in aged olfactory bulbs, as revealed by redox proteomics, are aldolase 1 and ferritin heavy chain [81]. The effects of aging on oxidative stress damage in the olfactory bulb have been further demonstrated in accelerated senescence-prone, short-lived (SAMP) mice when compared with accelerated senescence-resistant, longer lived (SAMR) strains [82]. Therefore, aging in the olfactory bulb is associated with increased oxidative stress and oxidative damage. Whether these modifications are augmented in PD is not known, but, needless to say, future work will help to increase our understanding of molecular alterations, other than those related to $\alpha$-synuclein, in the olfactory bulb and tract in PD.

A different approach has brought about interesting results. A series of PD patients underwent [(11)C]methyl-4piperidinyl propionate acetylcholinesterase brain PET emission tomography and olfactory testing with the University of Pennsylvania Smell Identification Test. The diagnosis of PD was confirmed by [(11)C]dihydrotetrabenazine vesicular monoamine transporter type 2 PET. Cholinergic denervation of the limbic archicortex was a more robust determinant of hyposmia than nigrostriatal dopaminergic denervation in subjects with moderately severe PD [83]. However, it is worth stressing that no apparent abnormalities in the cholinergic system appear to be present at stages 1 and 2 of Braak, and, therefore, cholinergic denervation of the limbic cortex is probably not the only factor accounting for olfactory disorder in early premotor stages of PD.

Disorders of olfaction also occur in familial PD but they appear to be more benign in certain familial cases, linked with LRRK2 or parkin mutations, than in sporadic PD $[84,85]$.

\section{Dysautonomia and Autonomic Nervous System in PD}

Early studies demonstrated the presence of LBs in the parasympathetic ganglia, sympathetic ganglia, and enteric nervous system in PD $[86,87]$. LBs are consistently found in the hypothalamus, sympathetic (intermediodorsal nucleus of the thoracic cord and sympathetic ganglia) and parasympathetic system (dorsal vagal and sacral parasympathetic nuclei, and peripheral parasympathetic ganglia), and enteric plexus [88-90]. Regarding central medullary autonomic areas, the number of catecholaminergic and serotoninergic neurons is not significantly reduced in $\mathrm{PD}$, although raphe neurons decline in number with disease progression [91]. Neuropathological studies in large cohorts of neurologically unimpaired aged individuals have shown that the autonomic nuclei of the spinal cord and the peripheral autonomic nervous system are affected early on by LB pathology [74, 92-94]. Finally, $\alpha$-synuclein-immunoreactive inclusions are seen in neurons of the Meissner's and Auerbach's plexuses and in the corresponding axons projecting into the mucosa $[56,95]$.

Sensitive immunohistochemical methods to detect phosphorylated $\alpha$-synuclein have revelealed multiorgan localization and gradient distribution of aberrant $\alpha$-synuclein deposits. The highest densities occurred in the spinal cord, paraspinal sympathetic ganglia, vagus nerve, gastrointestinal tract and endocrine organs. Within the gastrointestinal tract, the lower esophagus and the submandibular gland had higher numbers of inclusions than the colon and rectum [96].

The cardiovascular autonomic system is also affected in $\mathrm{PD}$, and alterations implicate both tyrosine hydroxylasepositive (extrinsic) and negative (intrinsic) nerves of the cardiac plexus [76, 97]. Functional studies have also demonstrated cardiac involvement in PD. [1231] metaiodobenzylguanidine (MIBG) myocardial scintigraphy has shown reduced MIBG uptake in PD [98-102]. Importantly, decreased MIBG uptake precedes neuronal loss in the sympathetic ganglia [103-105]. Interestingly, accumulation of $\alpha$-synuclein aggregates occurs in the distal axons of the cardiac sympathetic nervous system preceding that of neuronal somata or neurites in the paravertebral sympathetic ganglia, thus indicating a centripetal degeneration of the cardiac sympathetic nerve in PD [105]. Olfactory tests, polysomnographic studies and MIBG myocardial scintigraphy in combination may be used to discover early signatures of the disease [106]. Interestingly, cardiac sympathetic denervation precedes nigrostriatal loss in individuals bearing the E46K mutation in SNCA [107].

These observations point to an association between synuclein deposits and impaired function in the autonomic nervous system. But this does not imply a causal relationship between these events. Several aspects are still elusive and require further study. (i) Autonomic symptoms are not always present in PD. (ii) LB pathology in autonomic peripheral ganglia and plexus is not always associated with clinical symptoms. (iii) Little is known about the nature and composition of LBs in peripheral autonomic nervous system. (iv) No data are available about molecular changes preceding, or associated with, early and late stages of LB pathology in the autonomic peripheral nervous system. (v) Little is known about the alterations other than the accumulation of abnormal $\alpha$-synuclein that might cause altered autonomic functions in DLBs.

\section{Sleep Disorders}

Sleep disorders including sleep fragmentation, REM sleep behaviour disorders, and complex paroxysmal nocturnal motor behavioral disorders are common in PD [108-110], and they may precede by decades motor symptoms [111]. The neuropathological substrates are poorly understood although affected nuclei in the brain stem including the pedunculopontine nucleus probably play key roles [112]. The ventral visual stream appears involved in visuoperceptive alterations associated with REM disorders [113]. Finally, hypocretin (orexin) cell loss following an anterior to posterior gradient has been found in the hypothalamus of $\mathrm{PD}$ 
cases with disease progression $[114,115]$. This is not clearly accompanied by constant decrease in the expression levels of CSF orexin [116]. Whether orexin correlates with sleep attacks and its action is mediated by dopamine receptors 3 needs validation [117].

\section{Cognitive Impairment and the Cerebral Cortex in PD}

Changes in personality and moderate or mild cognitive debilitation are found in PD. Neuropsychiatric alterations and cognitive decline may occur at early stages of parkinsonism suggesting that they are an integral part of PD from the beginning of the disease in some patients. Characteristically, symptoms are often subtle at the beginning and difficult to detect without neuropsychological tests, although they become aggravated with progression of the disease. Deficits mainly affect executive function including working memory and visuospatial capacity. These are often accompanied by anxiety and depression, and excessive daytime sleepiness probably related with sleep disturbances (see $[118,119]$, for review).

Certain studies have shown an association between cortical LBs and cognitive impairment [120-123]. Yet other studies have not confirmed this assumption [57, 58, 124127]. Moreover, associated AD pathology has been suggested as an important cofactor in the progression of cognitive impairment in PD [58]. Additional studies have not clarified a predictive role of LBs in the occurrence of cognitive deficits $[128,129]$ although LB pathology correlates with visual hallucinations when present in the medial temporal lobe and visual areas $[130,131]$. Statistical analysis reveals that $\alpha$ synuclein aggregates in limbic regions are related to dementia in PD as well as to visual hallucinations when there is an underlying dementia [132].

Neuropathlogical studies in a large series have confirmed that staging of LB pathology is barely applicable to cognitive impairment and dementia. Only a percentage of cases showed a relationship between cortical LBs and cognitive impairment and dementia [127]. Taken together, these observations strongly indicate that cortical Lewy bodies are not per se causative of dementia, but rather indicators of aggregates of pathological synuclein. Other factors are probably more responsible of altered cognitive function in PD.

It must be stressed that tau phosphorylation and $\alpha$-synuclein phosphorylation are increased in synapticenriched fractions of frontal cortex homogenates in PD in the absence of LBs in the same tissue samples [133]. This indicates early $\alpha$-synuclein alterations at the synapse even in cases with no cognitive impairment [133]. Recent observations have further demonstrated the presence of small abnormal aggregates of $\alpha$-synuclein at the synapses $[134,135]$. Therefore, abnormal aggregates at the synapses in greater numbers than large cytoplasmic and neuritic aggregates (LBs and aberrant neurites, resp.) may account for impaired function in PD. These are important independent observations showing that synaptic pathology occurs in the absence of LBs and that the most common alteration in the cerebral cortex in PD is pathology at the synapses rather than the presence of LBs.

It is worth stressing that altered $\alpha$-synuclein may result in altered protein-protein interactions leading to altered synaptic function. Although these modifications are barely understood as yet, it is worth stressing that abnormal interactions have been reported between $\alpha$-synuclein and Rab3a, a protein involved in synaptic vesicle trafficking, Rab5, a protein involved in dopamine endocytosis, and Rab8, a protein engaged in transport [136]. Altered interactions have also been suggested between altered $\alpha$-synuclein and phospholipase C (PLC $\beta 1$ ), a signalling downstream step of metabotropic glutamate receptors [137].

In other words, LBs per se have no direct impact on clinical symptoms but other more subtle abnormalities are causative of impaired cortical function. In addition to abnormal accumulation of altered proteins at the cortical synapses, a series of convergent approaches may help to increase understanding of the different factors leading to impaired cerebral function in PD. Some of them relate to impaired dopaminergic, noradrenergic, cholinergic and serotoninergic innervation of the cerebral cortex; others, to intrinsic metabolic deficits.

Cognitive and executive deficits have been related, in part, to reduced dopaminergic innervation in the nigrostriatal and mesocortical dopaminergic systems compromising directly and indirectly, via alteration of the basal ganglia, prefrontal cortical function [138-142]. [18F] FDOPA uptake is reduced in frontal association areas in later stages of PD [143]. However, altered cognitive performance is not clearly related with impaired dopaminergic innervations of the cerebral cortex at early stages of the disease. PET studies with [11C] NNC112 and [18F] FDOPA have not shown significant associations between $\mathrm{D}(1)$ receptor density in the frontal cortex and performance at early stages of PD, in spite of a significant association between reduced [18F] FDOPA uptake in the putamen and poor performance in cognitive tests [144]. Along the same lines, attenuated dopamine release has been observed in the dorsal caudate but not in the medial prefrontal cortex in early PD patients [145].

Yet nondopaminergic systems are known to be damaged in PD, including the monoaminergic cells of the locus ceruleus, serotoninergic neurons of the raphe and cholinergic neurons of the nucleus basalis of Meynert [146-149].

Cholinergic deficits have been postulated as causative of frontal dysfunction in PD $[150,151]$. Recent studies have shown early alteration of the cholinergic innervation of the cerebral cortex in PD which increases in cases with dementia, thus correlating impaired cholinergic innervation and cognitive impairment [152-154].

In the same line, alteration of the serotonin transporter, as revealed by 123I-FP-CIT SPECT, has been observed in PD and with much more severe involvement in DLB, despite the comparable loss of striatal dopamine transporter [155].

Besides the loss of afferencies, primary impaired metabolism of the cerebral cortex may be causative of intrinsic cortical decay.

Cerebral glucose metabolism is reduced in the cerebral cortex in PD patients suffering from cognitive impairment 
[156]. Limited, mainly posterior, blood flow reductions have been reported in PD cases with mild cognitive deficits assessed by rCB scintigraphic study using TC-HMPAOSPECT [157]. Metabolic and neuroimaging observations have recently documented decreased prefrontal and parietal 18F-fluorodeoxyglycose uptake in PD cases with mild cognitive deficits $[158,159]$. Parallel conclusions have been obtained using magnetic resonance; T1-weighed images and mean diffusitivity and fractional anisotropy values are increased in the frontal cortex in PD $[160,161]$. White matter hyperintensities are more frequent in PD cases with altered cognition than in cases with preserved cognitive functions [162]. Yet vascular abnormalities are very common in aged patients with PD [163], and we cannot rule out the possibility that white matter alterations are related to associate vascular/circulatory lesions rather than to primary lesions of PD.

A detailed discussion of molecular events leading to intrinsic cortical deficiencies is provided in the following paragraph.

\section{Mitochondria and Energy Machinery Failure in the Cerebral Cortex in PD}

Classical studies revealed abnormalities in complex I of the respiratory chain in the substantia nigra in sporadic PD (see [164], for review). More recently, several genes encoding proteins relevant to maintaining mitochondrial integrity have been shown to be causative of familial PD $[165,166]$. These data further reinforce the role of mitochondria in the pathogenesis of PD. Interestingly, several mutant proteins associated with familial PD are linked to mitochondria [167]. DJ1 is localized in the mitochondria and modulates responses to oxidative stress $[168,169]$. PINK1 is a protein kinase localized in the mitochondria in which mutations in the kinase domain are associated with mitochondrial deficits [170]. Furthermore, PINK1 is required for mitochondrial function as it interacts with and complements parkin [171173]. LRRK2 is a kinase localized in the outer mitochondrial membrane [174]. Finally, HtrA2 is localized in the mitochondria and is involved in apoptosis [175]. Deficits in mitochondrial function have also been identified in patients with DJ1, parkin and PINK1 mutations [176]. Interaction of these different gene products seems necessary to maintain mitochondrial homeostasis [177-179]. Moreover, mutations in mitochondrial DNA have also been noted in familial parkinsonism due to PINK1 mutations [180].

These observations point to the possibility that mitochondrial dysfunction plays a crucial role not only in dopaminergic neurons of the substantia nigra but also in the whole brain. In this line, brain cortex and mitochondrial $\mathrm{O}_{2}$ uptake and complex I activity are significantly lower in $\mathrm{PD}$, whereas mitochondrial nitric oxide synthase activity, cytochrome content, expression of Mn-superoxide dismutase (SOD2), mitochondrial mass, and oxidative damage are significantly higher in the frontal cortex in PD. The decreases in tissue and mitochondrial $\mathrm{O}_{2}$ uptake and in complex I activity are considered the consequences of mitochondrial oxidative damage in the cerebral cortex in $\mathrm{PD}[181,182]$.
Moreover, subunits of mitochondrial complex I are oxidatively damaged, functionally impaired and misassembled in PD [183]. Finally, phosphorus and proton magnetic resonance spectroscopy confirm generalized mitochondrial dysfunction in PD [184]. It is not reckless to assume that loss of mitochondrial function is a primary cause of energy production decay.

Increased oxidative damage has also been detected in the frontal cortex, in addition to that reported several years ago in the substantia nigra, in PD [185]. Several key proteins are targets of oxidative damage in the frontal cortex even at very early stages of PD-related pathology, including $\alpha$-synuclein, $\beta$-synuclein and SOD2 $[186,187]$. Other relevant proteins are also oxidatively damaged in PD: UCHL1, Cu, Zn-superoxide dismutase and DJ-1 [188190]. In addition, increased oxidative damage of aldolase A, enolase 1 and glyceraldehyde dehydrogenase (GAPDH), all of them involved in glycolysis and energy metabolism, is found in the frontal cortex in premotor stages of PD and in established parkinsonian PD disease as well [191]. In the same line of generalized oxidative stress and stress responses is the observation of increased glutahione peroxidase, one of the main antioxidant enzymes inactivating hydrogen peroxide, in microglial cells of the gray matter and white matter in PD and DLB [192].

Recent observations have shown abnormal lipid composition in the frontal cortex at very early stages of PD-related pathology with significantly increased expression levels of the highly peroxidizable docosahexanoic acid (DHA) and increased peroxidability index [186]. Together, these features indicate that mitochondrial abnormalities, altered lipid composition and increased oxidative damage of proteins involved in the cytoskeleton, neurotransmission, mitochondrial function and energy metabolism occur at early, premotor stages of PD and persist with disease progression [193]. In the same line, recent observations have shown impaired lipid composition of lipid rafts with dramatic reductions in their contents of n-3 and n-6 LCPUFA, especially docosahexaenoic acid (22:6-n3) and arachidonic acid (20:4n-6), and increased saturated fatty acids (16:0 and 18:0) when compared with control brains, thus leading to increased membrane viscosity and, probably, to increased energy demands [194].

The term "exhausted neuron" was employed in Alzheimer's disease to designate a combination of metabolic events leading to impaired and persistent energy production accompanied by increased energy demands that may be detected at very early stages of disease even in cases without overt clinical symptoms of cognitive impairment and dementia [195]. A similar scenario also occurs, albeit with different targets (different primary involvement of respiratory chain complexes, different lipoxidative and glycoxidative damage, different alteration of membrane lipid composition), in PD. It may be postulated that intrinsic exhaustion of neurons plays an important role in the subtle but inexorable progression of clinical symptoms once thresholds of neuronal tolerance cannot longer support energy demands.

Oxidative damage in cerebral cortex has also been reported in familial cases bearing the LRRK2 mutation in 
TABLE 1: Convergence of altered metabolic events in the cerebral cortex in Parkinson disease.

Altered cortical innervation
(i) $\downarrow$ Dopamine (nigrostriatal and mesocortical pathways):
indirect and direct pathways
(ii) $\downarrow$ Noradrenaline (locus ceruleus)
(iii) $\downarrow$ Serotonine (raphe nuclei)
(iv) $\downarrow$ Acetylcholine (nuclei of the basal forebrain)

Synaptic pathology

(i) $\uparrow$ Tau phosphorylation in synaptic fractions

(ii) $\uparrow \alpha$-synuclein phosphorylation in synaptic fractions

(iii) Small $\alpha$-synuclein aggregates at the synapses

Altered $\alpha$-synuclein and $\alpha$-synuclein interactions

(i) Oxidation and phosphorylation of $\alpha$-synuclein

(ii) Abnormal synuclein interactions with
(a) rab3a: possible altered synaptic traffic
(b) rab5: possible altered endocytosis
(c) rab8: possible altered transport
(d) PLC $\beta$ : altered mGluR1 signalling

Altered mitochondria

(i) $\uparrow$ Mitochondrial mass

(ii) $\downarrow$ Complex I of the respiratory chain

(iii) $\downarrow$ Mitochondrial $\mathrm{O}_{2}$ uptake

(iv) Oxidative damage of subunits of mitochondrial complex I and DJ1

(v) (altered DJ1, PINK1, LRRK2, and Htr2 in familial PD)

Increased oxidative damage

(i) $\uparrow$ Lipoxidative and glycoxidative damage of proteins and oxidative damage of DNA

(ii) $\uparrow$ Oxidative damage of proteins linked with glycolysis and energy metabolism

(iii) $\uparrow$ Oxidative damage of superoxide dismutase 2

(iv) $\uparrow$ Oxidative damage of $\beta$-synuclein, $\alpha$-synuclein, cytoskeletal proteins and UCHL1

Altered composition of membrane lipids in the grey matter

(i) Total homogenates

(ii) Lipid rafts: $\uparrow$ viscosity

Late, secondary events

(i) Synaptic loss

(ii) Lewy bodies and neurites

(iii) Neuronal death

the absence of apparent cognitive impairment and in the absence of LBs in cerebral cortex [196]. This further supports the concept that the cerebral cortex is affected in PD independently of its being associated (or not) with the presence of LBs.

Altered metabolic events in the cerebral cortex in Parkinson disease are summarized in Table 1.

\section{Psychiatric Symptoms and Neuropathological Correlates}

Anhedonia, apathy, anxiety, panic attacks, social phobias and depression also occur in patients with PD even at early premotor stages and not related to medication [68, 197, 198]. Psychotic symptoms are frequent such as visual and auditory hallucinations, agitated confusion, vivid dreaming, delirium and delusions [199-203]. The molecular substrates of such alterations are scarcely known but several hypothesis have been proposed including imbalance between serotoninergic and dopaminergic systems, cortical cholinergic deficiency and overstimulation of mesocorticolimbic dopamine receptors [201, 203-207]. Neuropathological studies have helped little to increase understanding of depression and psychoses although recent observations have suggested that depression is related more to catecholaminergic than serotoninergic dysfunction [208], and that hallucinations correlate with the number of Lewy bodies in the temporal lobe, claustrum and visual cortex [130, 131].

Finally, an interesting and not fully understood paradigm is the consequence of alterations in amygdala in $\mathrm{PD}$ in spite of its constant involvement in classical PD and its almost unique alteration in amygdala-predominant LBD. The amygdala is activated in appetitive and emotional learning [209, 210]. Yet decreased responsiveness is found in the amygdala in PD in the face of fearful facial expressions, facial, prosodic and written verbal stimuli, and decisionmaking and facial emotion recognition [211-213]. Whether these modifications are the result of impaired dopaminergic regulation [214] or the consequence of primary pathology in the amygdala is not known.

\section{Acknowledgments}

Work carried out in the Institute of Neuropathology was partially funded by Grants from the Spanish Ministry of Health, Instituto de Salud Carlos III PI05/1570, PI05/2214 and PI08/0582, PET2007-0397, and supported by the European Commission: BrainNet Europe II, LSHM-CT-2004503039 and INDABIP FP6-2005-LIFESCIHEALTH-7 Molecular Diagnostics. Thanks are due to T. Yohannan for the editorial help.

\section{References}

[1] L. S. Forno, "Neuropathology of Parkinson's disease," Journal of Neuropathology and Experimental Neurology, vol. 55, no. 3, pp. 259-272, 1996.

[2] K. Jellinger and Y. Mizuno, "Parkinson's disease," in Neurodegeneration: The Molecular Pathology of Dementia and Movement Disorders, D. Dickson, Ed., pp. 159-187, ISN Neuropathol Press, Basel, Switzerland, 2003.

[3] H. Braak, D. Sandmann-Keil, W. Gai, and E. Braak, "Extensive axonal Lewy neurites in Parkinson's disease: a novel pathological feature revealed by $\alpha$-synuclein immunocytochemistry," Neuroscience Letters, vol. 265, no. 1, pp. 67-69, 1999. 
[4] D. W. Dickson, " $\alpha$-Synuclein and the Lewy body disorders," Current Opinion in Neurology, vol. 14, no. 4, pp. 423-432, 2001.

[5] M. Goedert, "Parkinson's disease and other $\alpha$-synucleinopathies," Clinical Chemistry and Laboratory Medicine, vol. 39, no. 4, pp. 308-312, 2001.

[6] H. Braak and K. Del Tredici, "Cortico-basal ganglia-cortical circuitry in Parkinson's disease reconsidered," Experimental Neurology, vol. 212, no. 1, pp. 226-229, 2008.

[7] D. W. Dickson, H. Braak, J. E. Duda et al., "Neuropathological assessment of Parkinson's disease: refining the diagnostic criteria," The Lancet Neurology, vol. 8, no. 12, pp. 1150-1157, 2009.

[8] P. G. Ince and I. G. McKeith, "Dementia with Lewy bodies," in Neurodegeneration, D. Dickson, Ed., pp. 188-199, ISN Neuropath Press, Basel, Switzerland, 2003.

[9] I. McKeith, "Clinical aspects of dementia with Lewy bodies," in Handbook of Clinical Neurology, D. C. Duyckaerts and I. Litvan, Eds., vol. 89, pp. 306-311, Elsevier, New York, NY, USA, 3rd edition, 2008.

[10] J. Lowe, "Neuropathology of dementia with Lewy bodies," in Handbook of Clinical Neurology, D. C. Duyckaerts and I. Litvan, Eds., vol. 89, pp. 321-330, Elsevier, New York, NY, USA, 3rd edition, 2008.

[11] C. W. Shults, "Lewy bodies," Proceedings of the National Academy of Sciences of the United States of America, vol. 103, no. 6, pp. 1661-1668, 2006.

[12] K. Wakabayashi, K. Tanji, F. Mori, and H. Takahashi, “The Lewy body in Parkinson's disease: molecules implicated in the formation and degradation of $\alpha$-synuclein aggregates," Neuropathology, vol. 27, no. 5, pp. 494-506, 2007.

[13] J. B. Leverenz, I. Umar, Q. Wang et al., "Proteomic identification of novel proteins in cortical Lewy bodies," Brain Pathology, vol. 17, no. 2, pp. 139-145, 2007.

[14] Q. Xia, L. Liao, D. Cheng et al., "Proteomic identification of novel proteins associated with Lewy bodies," Frontiers in Bioscience, vol. 13, no. 10, pp. 3850-3856, 2008.

[15] M. G. Spillantini, M. L. Schmidt, V. M. Y. Lee, J. Q. Trojanowski, R. Jakes, and M. Goedert, " $\alpha$-synuclein in Lewy bodies,” Nature, vol. 388, no. 6645, pp. 839-840, 1997.

[16] K. Wakabayashi, K. Matsumoto, K. Takayama, M. Yoshimoto, and $\mathrm{H}$. Takahashi, "NACP, a presynaptic protein, immunoreactivity in Lewy bodies in Parkinson's disease," Neuroscience Letters, vol. 249, pp. 180-182, 1997.

[17] M. Baba, S. Nakajo, P. H. Tu et al., "Aggregation of $\alpha$ synuclein in Lewy bodies of sporadic Parkinson's disease and dementia with Lewy bodies," American Journal of Pathology, vol. 152, no. 4, pp. 879-884, 1998.

[18] M. Hashimoto and E. Masliah, "Alpha-synuclein in Lewy body disease and Alzheimer's disease," Brain Pathology, vol. 9, no. 4, pp. 707-720, 1999.

[19] J. E. Duda, B. I. Giasson, Q. Chen et al., "Widespread nitration of pathological inclusions in neurodegenerative synucleinopathies," American Journal of Pathology, vol. 157, no. 5, pp. 1439-1445, 2000.

[20] B. I. Giasson, J. E. Duda, I. V. J. Murray et al., "Oxidative damage linked to neurodegeneration by selective $\alpha$-synuclein nitration in synucleinopathy lesions," Science, vol. 290, no. 5493, pp. 985-989, 2000.

[21] H. Fujiwara, M. Hasegawa, N. Dohmae et al., " $\alpha$-synuclein is phosphorylated in synucleinopathy lesions," Nature Cell Biology, vol. 4, no. 2, pp. 160-164, 2002.
[22] T. Iwatsubo, "Aggregation of $\alpha$-synuclein in the pathogenesis of Parkinson's disease," Journal of Neurology, Supplement, vol. 250, supplement 3, pp. 11-14, 2003.

[23] J. P. Anderson, D. E. Walker, J. M. Goldstein et al., "Phosphorylation of Ser-129 is the dominant pathological modification of $\alpha$-synuclein in familial and sporadic Lewy body disease," Journal of Biological Chemistry, vol. 281, no. 40, pp. 29739-29752, 2006.

[24] M. H. Polymeropoulos, C. Lavedan, E. Leroy et al., "Mutation in the $\alpha$-synuclein gene identified in families with Parkinson's disease," Science, vol. 276, no. 5321, pp. 2045-2047, 1997.

[25] R. Krüger, W. Kuhn, T. Müller et al., "Ala30Pro mutation in the gene encoding $\alpha$-synuclein in Parkinson's disease," Nature Genetics, vol. 18, no. 2, pp. 106-108, 1998.

[26] J. J. Zarranz, J. Alegre, J. C. Gómez-Esteban et al., "The new mutation, E46K, of $\alpha$-synuclein causes Parkinson and Lewy body dementia," Annals of Neurology, vol. 55, no. 2, pp. 164173, 2004.

[27] A. B. Singleton, M. Farrer, J. Johnson et al., " $\alpha$-synuclein locus triplication causes Parkinson's disease," Science, vol. 302, no. 5646, p. 841, 2003.

[28] M. C. Chartier-Harlin, J. Kachergus, C. Roumier et al., " $\alpha$ synuclein locus duplication as a cause of familial Parkinson's disease," The Lancet, vol. 364, no. 9440, pp. 1167-1169, 2004.

[29] P. Ibáñez, A. M. Bonnet, B. Débarges et al., "Causal relation between $\alpha$-synuclein gene duplication and familial Parkinson's disease," The Lancet, vol. 364, no. 9440, pp. 11691171, 2004.

[30] K. Nishioka, S. Hayashi, M. J. Farrer et al., "Clinical heterogeneity of $\alpha$-synuclein gene duplication in Parkinson's disease," Annals of Neurology, vol. 59, no. 2, pp. 298-309, 2006.

[31] A. Jowaed, I. Schmitt, O. Kaut, and U. Wüllner, "Methylation regulates alpha-synuclein expression and is decreased in Parkinson's disease patients' brains," Journal of Neuroscience, vol. 30, no. 18, pp. 6355-6359, 2010.

[32] E. Doxakis, "Post-transcriptional regulation of $\alpha$-synuclein expression by mir-7 and mir-153," Journal of Biological Chemistry, vol. 285, no. 17, pp. 12726-12734, 2010.

[33] E. Junn, K. W. Lee, S. J. Byeong, T. W. Chan, J. Y. Im, and M. M. Mouradian, "Repression of $\alpha$-synuclein expression and toxicity by microRNA-7," Proceedings of the National Academy of Sciences of the United States of America, vol. 106, no. 31, pp. 13052-13057, 2009.

[34] G. Wang, J. M. van der Walt, G. Mayhew et al., "Variation in the miRNA-433 binding site of FGF20 confers risk for Parkinson disease by overexpression of $\alpha$-synuclein," American Journal of Human Genetics, vol. 82, no. 2, pp. 283289, 2008.

[35] T. Kitada, S. Asakawa, N. Hattori et al., "Mutations in the parkin gene cause autosomal recessive juvenile parkinsonism," Nature, vol. 392, no. 6676, pp. 605-608, 1998.

[36] V. Bonifati, P. Rizzu, M. J. Van Baren et al., "Mutations in the DJ-1 gene associated with autosomal recessive early-onset parkinsonism," Science, vol. 299, no. 5604, pp. 256-259, 2003.

[37] E. M. Valente, P. M. Abou-Sleiman, V. Caputo et al., "Hereditary early-onset Parkinson's disease caused by mutations in PINK1," Science, vol. 304, no. 5674, pp. 1158-1160, 2004.

[38] A. Zimprich, S. Biskup, P. Leitner et al., "Mutations in LRRK2 cause autosomal-dominant parkinsonism with pleomorphic pathology," Neuron, vol. 44, no. 4, pp. 601-607, 2004. 
[39] C. Paisán-Ruíz, S. Jain, E. W. Evans et al., "Cloning of the gene containing mutations that cause PARK8-linked Parkinson's disease," Neuron, vol. 44, no. 4, pp. 595-600, 2004.

[40] K. M. Strauss, L. M. Martins, H. Plun-Favreau et al., "Loss of function mutations in the gene encoding Omi/HtrA2 in Parkinson's disease," Human Molecular Genetics, vol. 14, no. 15, pp. 2099-2111, 2005.

[41] E. Leroy, R. Boyer, G. Auburger et al., "The ubiquitin pathway in Parkinson's disease,” Nature, vol. 395, no. 6701, pp. 451452, 1998.

[42] E. Sidransky, M. A. Nalls, J. O. Aasly et al., "Multicenter analysis of glucocerebrosidase mutations in Parkinson's disease," New England Journal of Medicine, vol. 361, no. 17, pp. 16511661, 2009.

[43] T. Gasser, "Molecular pathogenesis of Parkinson disease: insights from genetic studies," Expert reviews in molecular medicine, vol. 11, article e22, 2009.

[44] B. Thomas and M. F. Beal, "Parkinson's disease," Human molecular genetics, vol. 16, pp. R183-194, 2007.

[45] J. Hardy, P. Lewis, T. Revesz, A. Lees, and C. Paisan-Ruiz, "The genetics of Parkinson's syndromes: a critical review," Current Opinion in Genetics and Development, vol. 19, no. 3, pp. 254-265, 2009.

[46] G. Santpere and I. Ferrer, "LRRK2 and neurodegeneration," Acta Neuropathologica, vol. 117, no. 3, pp. 227-246, 2009.

[47] L. Samaranch, O. Lorenzo-Betancor, J. M. Arbelo et al., "PINK1-linked parkinsonism is associated with Lewy body pathology," Brain, vol. 133, no. 4, pp. 1128-1142, 2010.

[48] H. Braak, K. Del Tredici, H. Bratzke, J. Hamm-Clement, D. Sandmann-Keil, and U. Rüb, "Staging of the intracerebral inclusion body pathology associated with idiopathic Parkinson's disease (preclinical and clinical stages)," Journal of Neurology, Supplement, vol. 249, no. 3, pp. III1-III5, 2002.

[49] H. Braak, K. Del Tredici, U. Rüb, R. A. I. De Vos, E. N. H. Jansen Steur, and E. Braak, "Staging of brain pathology related to sporadic Parkinson's disease," Neurobiology of Aging, vol. 24, no. 2, pp. 197-211, 2003.

[50] H. Braak, E. Ghebremedhin, U. Rüb, H. Bratzke, and K. Del Tredici, "Stages in the development of Parkinson's diseaserelated pathology," Cell and Tissue Research, vol. 318, no. 1, pp. 121-134, 2004.

[51] R. Frigerio, H. Fujishiro, D. M. Maraganore et al., "Comparison of risk factor profiles in incidental Lewy body disease and Parkinson disease," Archives of Neurology, vol. 66, no. 9, pp. 1114-1119, 2009.

[52] H. Uchikado, W.-L. Lin, M. W. Delucia, and D. W. Dickson, "Alzheimer disease with amygdala Lewy bodies: a distinct form of $\alpha$-synucleinopathy," Journal of Neuropathology and Experimental Neurology, vol. 65, no. 7, pp. 685-697, 2006.

[53] K. Kosaka, "Dementia and neuropathology in Lewy body disease," Advances in neurology, vol. 60, pp. 456-463, 1993.

[54] J. Zaccai, C. Brayne, I. McKeith, F. Matthews, and P. G. Ince, " MRC cognitive function, ageing neuropathology study, patterns and stages of $\alpha$-synucleinopathy: relevance in a population-based cohort," Neurology, vol. 70, pp. 1042-1048, 2008.

[55] K. A. Jellinger, "Lewy body-related $\alpha$-synucleinopathy in the aged human brain," Journal of Neural Transmission, vol. 111, no. 10-11, pp. 1219-1235, 2004.

[56] H. Braak, R. A. I. De Vos, J. Bohl, and K. Del Tredici, "Gastric $\alpha$-synuclein immunoreactive inclusions in Meissner's and Auerbach's plexuses in cases staged for Parkinson's diseaserelated brain pathology," Neuroscience Letters, vol. 396, no. 1, pp. 67-72, 2006.
[57] K. A. Jellinger, "A critical reappraisal of current staging of Lewy-related pathology in human brain," Acta Neuropathologica, vol. 116, no. 1, pp. 1-16, 2008.

[58] K. A. Jellinger, "A critical evaluation of current staging of $\alpha$ synuclein pathology in Lewy body disorders," Biochimica et Biophysica Acta, vol. 1792, no. 7, pp. 730-740, 2009.

[59] K. R. Chaudhuri, L. Yates, and P. Martinez-Martin, "The non-motor symptom complex of Parkinson's disease: a comprehensive assessment is essential," Current Neurology and Neuroscience Reports, vol. 5, no. 4, pp. 275-283, 2005.

[60] R. B. Postuma, A. E. Lang, J. Massicotte-Marquez, and J. Montplaisir, "Potential early markers of Parkinson disease in idiopathic REM sleep behavior disorder," Neurology, vol. 66, no. 6, pp. 845-851, 2006.

[61] A. Iranzo, J. L. Molinuevo, J. Santamaría et al., "Rapid-eyemovement sleep behaviour disorder as an early marker for a neurodegenerative disorder: a descriptive study," Lancet Neurology, vol. 5, no. 7, pp. 572-577, 2006.

[62] A. Siderowf and M. B. Stern, "Preclinical diagnosis of Parkinson's disease: are we there yet?" Current Neurology and Neuroscience Reports, vol. 6, no. 4, pp. 295-301, 2006.

[63] E. Tolosa, Y. Compta, and C. Gaig, "The premotor phase of Parkinson's disease," Parkinsonism and Related Disorders, vol. 13, pp. S2-S7, 2007.

[64] W. Poewe, "Dysautonomia and cognitive dysfunction in Parkinson's disease," Movement Disorders, vol. 22, supplement 17, pp. S374-S378, 2007.

[65] T. Ziemssen and H. Reichmann, "Non-motor dysfunction in Parkinson's disease," Parkinsonism and Related Disorders, vol. 13, no. 6, pp. 323-332, 2007.

[66] B. Herting, S. Schulze, H. Reichmann, A. Haehner, and T. Hummel, "A longitudinal study of olfactory function in patients with idiopathic Parkinson's disease," Journal of Neurology, vol. 255, no. 3, pp. 367-370, 2008.

[67] E. C. H. Wolters and H. Braak, "Parkinson's disease: premotor clinico-pathological correlations," Journal of Neural Transmission, Supplement, no. 70, pp. 309-319, 2006.

[68] W. Poewe, "Non-motor symptoms in Parkinson's disease," European Journal of Neurology, vol. 15, supplement 1, pp. 1420, 2008.

[69] G. W. Ross, H. Petrovitch, R. D. Abbott et al., "Association of olfactory dysfunction with risk for future Parkinson's disease," Annals of Neurology, vol. 63, no. 2, pp. 167-173, 2008.

[70] G. Natale, L. Pasquali, S. Ruggieri, A. Paparelli, and F. Fornai, "Parkinson's disease and the gut: a well known clinical association in need of an effective cure and explanation," Neurogastroenterology and Motility, vol. 20, no. 7, pp. 741749, 2008.

[71] S. E. Daniel and C. H. Hawkes, "Preliminary diagnosis of Parkinson's disease by olfactory bulb pathology," The Lancet, vol. 340, no. 8812, p. 186, 1992.

[72] R. K. B. Pearce, C. H. Hawkes, and S. E. Daniel, "The anterior olfactory nucleus in Parkinson's disease," Movement Disorders, vol. 10, no. 3, pp. 283-287, 1995.

[73] K. Del Tredici, U. Rüb, R. A. I. De Vos, J. R. E. Bohl, and H. Braak, "Where does Parkinson disease pathology begin in the brain?" Journal of Neuropathology and Experimental Neurology, vol. 61, no. 5, pp. 413-426, 2002.

[74] A. Bloch, A. Probst, H. Bissig, H. Adams, and M. Tolnay, " $\alpha$-Synuclein pathology of the spinal and peripheral autonomic nervous system in neurologically unimpaired elderly subjects," Neuropathology and Applied Neurobiology, vol. 32, no. 3, pp. 284-295, 2006. 
[75] P. S. Hubbard, M. M. Esiri, M. Reading, R. McShane, and Z. Nagy, "Alpha-synuclein pathology in the olfactory pathways of dementia patients," Journal of Anatomy, vol. 211, no. 1, pp. 117-124, 2007.

[76] H. Fujishiro, R. Frigerio, M. Burnett et al., "Cardiac sympathetic denervation correlates with clinical and pathologic stages of Parkinson's disease," Movement Disorders, vol. 23, no. 8, pp. 1085-1092, 2008.

[77] I. Ubeda-Bañon, D. Saiz-Sanchez, C. De La Rosa-Prieto, L. Argandoña-Palacios, S. Garcia-Muñozguren, and A. Martinez-Marcos, " $\alpha$-Synucleinopathy in the human olfactory system in Parkinson's disease: involvement of calciumbinding protein- and substance P-positive cells," Acta Neuropathologica, vol. 119, no. 6, pp. 723-735, 2010.

[78] T. G. Beach, C. L. White 3rd, C. L. Hladik et al., "Arizona Parkinson's Disease Consortium. Olfactory bulb $\alpha$ synucleinopathy has high specificity and sensitivity for Lewy body disorders," Acta Neuropathologica, vol. 117, no. 2, pp. 215-216, 2009.

[79] L. Parkkinen, L. Silveira-Moriyama, J. L. Holton, A. J. Lees, and T. Revesz, "Can olfactory bulb biopsy be justified for the diagnosis of Parkinson's disease? Comments on "olfactory bulb $\alpha$-synucleinopathy has high specificity and sensitivity for Lewy body disorders"', Acta Neuropathologica, vol. 117, no. 2, pp. 213-214, 2009.

[80] E. Biagiotti, P. Ferri, R. Dringen, P. Del Grande, and P. Ninfali, "Glucose-6-phosphate dehydrogenase and NADPHconsuming enzymes in the rat olfactory bulb," Journal of Neuroscience Research, vol. 80, no. 3, pp. 434-441, 2005.

[81] R. A. Vaishnav, M. L. Getchell, H. F. Poon et al., "Oxidative stress in the aging murine olfactory bulb: redox proteomics and cellular localization," Journal of Neuroscience Research, vol. 85, no. 2, pp. 373-385, 2007.

[82] M. Hosokawa, "A higher oxidative status accelerates senescence and aggravates age-dependent disorders in SAMP strains of mice," Mechanisms of Ageing and Development, vol. 123, no. 12, pp. 1553-1561, 2002.

[83] N. I. Bohnen, M. L. T. M. Müller, V. Kotagal et al., "Olfactory dysfunction, central cholinergic integrity and cognitive impairment in Parkinson's disease," Brain, vol. 133, no. 6, pp. 1747-1754, 2010.

[84] D. G. Healy, M. Falchi, S. S. O'Sullivan et al., "Phenotype, genotype, and worldwide genetic penetrance of LRRK2associated Parkinson's disease: a case-control study," The Lancet Neurology, vol. 7, no. 7, pp. 583-590, 2008.

[85] G. Kägi, C. Klein, N. W. Wood et al., "Nonmotor symptoms in Parkin gene-related parkinsonism," Movement Disorders, vol. 25, no. 9, pp. 1279-1284, 2010.

[86] K. Wakabayashi, H. Takahashi, E. Ohama, and F. Ikuta, "Parkinson's disease: an immunohistochemical study of Lewy body-containing neurons in the enteric nervous system," Acta Neuropathologica, vol. 79, no. 6, pp. 581-583, 1990.

[87] S. Takeda, K. Yamazaki, T. Miyakawa, and H. Arai, "Parkinson's disease with involvement of the parasympathetic ganglia," Acta Neuropathologica, vol. 86, no. 4, pp. 397-398, 1993.

[88] K. Wakabayashi and H. Takahashi, "Neuropathology of autonomic nervous system in Parkinson's disease," European Neurology, vol. 38, supplement 2, pp. 2-7, 1997.

[89] K. Hague, P. Lento, S. Morgello, S. Caro, and H. Kaufmann, "The distribution of Lewy bodies in pure autonomic failure: autopsy findings and review of the literature," Acta Neuropathologica, vol. 94, no. 2, pp. 192-196, 1997.
[90] G. Micieli, P. Tosi, S. Marcheselli, and A. Cavallini, "Autonomic dysfunction in Parkinson's disease," Neurological Sciences, vol. 24, supplement 1, pp. S32-S34, 2003.

[91] E. E. Benarroch, A. M. Schmeichel, P. A. Low, B. F. Boeve, P. Sandroni, and J. E. Parisi, "Involvement of medullary regions controlling sympathetic output in Lewy body disease," Brain, vol. 128, no. 2, pp. 338-344, 2005.

[92] A. Minguez-Castellanos, C. E. Chamorro, F. Escamilla-Sevilla et al., "Do $\alpha$-synuclein aggregates in autonomic plexuses predate Lewy body disorders?: a cohort study," Neurology, vol. 68, no. 23, pp. 2012-2018, 2007.

[93] A. Probst, A. Bloch, and M. Tolnay, "New insights into the pathology of Parkinson's disease: does the peripheral autonomic system become central?" European Journal of Neurology, vol. 15, supplement 1, pp. 1-4, 2008.

[94] M. Oinas, A. Paetau, L. Myllykangas, I. L. Notkola, H. Kalimo, and T. Polvikoski, " $\alpha$-Synuclein pathology in the spinal cord autonomic nuclei associates with $\alpha$-synuclein pathology in the brain: a population-based Vantaa $85+$ study," Acta Neuropathologica, vol. 119, no. 6, pp. 715-722, 2010 .

[95] K. Wakabayashi, H. Takahashi, S. Takeda, E. Ohama, and F. Ikuta, "Parkinson's disease: the presence of Lewy bodies in Auerbach's and Meissner's plexuses," Acta Neuropathologica, vol. 76, no. 3, pp. 217-221, 1988.

[96] T. G. Beach, C. H. Adler, L. I. Sue et al., “Arizona Parkinson's Disease Consortium. Multi-organ distribution of phosphorylated $\alpha$-synuclein histopathology in subjects with Lewy body disorders," Acta Neuropathologica, vol. 119, no. 6, pp. 689-702, 2010.

[97] K. Iwanaga, K. Wakabayashi, M. Yoshimoto et al., "Lewy body-type degeneration in cardiac plexus in Parkinson's and incidental Lewy body diseases," Neurology, vol. 52, no. 6, pp. 1269-1271, 1999.

[98] H. Takatsu, H. Nishida, H. Matsuo et al., "Cardiac sympathetic denervation from the early stage of Parkinson's disease: clinical and experimental studies with radiolabeled MIBG," Journal of Nuclear Medicine, vol. 41, no. 1, pp. 71-77, 2000.

[99] J. Mitsui, Y. Saito, T. Momose et al., "Pathology of the sympathetic nervous system corresponding to the decreased cardiac uptake in 123I-metaiodobenzylguanidine (MIBG) scintigraphy in a patient with Parkinson disease," Journal of the Neurological Sciences, vol. 243, no. 1-2, pp. 101-104, 2006.

[100] K. Kashihara, M. Ohno, S. Kawada, and Y. Okumura, "Reduced cardiac uptake and enhanced washout of123IMIBG in pure autonomic failure occurs conjointly with Parkinson's disease and dementia with Lewy bodies," Journal of Nuclear Medicine, vol. 47, no. 7, pp. 1099-1101, 2006.

[101] H. Oka, M. Morita, K. Onouchi, M. Yoshioka, S. Mochio, and K. Inoue, "Cardiovascular autonomic dysfunction in dementia with Lewy bodies and Parkinson's disease," Journal of the Neurological Sciences, vol. 254, no. 1-2, pp. 72-77, 2007.

[102] H. Sawada, T. Oeda, K. Yamamoto et al., "Diagnostic accuracy of cardiac metaiodobenzylguanidine scintigraphy in Parkinson disease," European Journal of Neurology, vol. 16, no. 2, pp. 174-182, 2009.

[103] S. Orimo, T. Amino, Y. Itoh et al., "Cardiac sympathetic denervation precedes neuronal loss in the sympathetic ganglia in Lewy body disease," Acta Neuropathologica, vol. 109, no. 6, pp. 583-588, 2005.

[104] S. Orimo, A. Takahashi, T. Uchihara et al., "Degeneration of cardiac sympathetic nerve begins in the early disease process of Parkinson's disease," Brain Pathology, vol. 17, no. 1, pp. 2430, 2007. 
[105] S. Orimo, T. Uchihara, A. Nakamura et al., "Axonal $\alpha$-synuclein aggregates herald centripetal degeneration of cardiac sympathetic nerve in Parkinson's disease," Brain, vol. 131, no. 3, pp. 642-650, 2008.

[106] K. Stiasny-Kolster, Y. Doerr, J. C. Möller et al., "Combination of 'idiopathic' REM sleep behaviour disorder and olfactory dysfunction as possible indicator for $\alpha$-synucleinopathy demonstrated by dopamine transporter FP-CIT-SPECT," Brain, vol. 128, no. 1, pp. 126-137, 2005.

[107] B. Tijero, J. C. Gomez-Esteban, V. Llorens et al., "Cardiac sympathetic denervation precedes nigrostriatal loss in the E46K mutation of the $\alpha$-synuclein gene (SNCA)," Clinical Autonomic Research, vol. 20, no. 4, pp. 267-269, 2010.

[108] C. G. Goetz, B. Ouyang, A. Negron, and G. T. Stebbins, "Hallucinations and sleep disorders in $\mathrm{PD}$ : ten-year prospective longitudinal study," Neurology, vol. 75, no. 20, pp. 1773$1779,2010$.

[109] R. Manni, M. Terzaghi, A. Repetto, R. Zangaglia, and C. Pacchetti, "Complex paroxysmal nocturnal behaviors in Parkinson's disease," Movement Disorders, vol. 25, no. 8, pp. 985-990, 2010.

[110] B. F. Boeve, "REM sleep behavior disorder: updated review of the core features, the REM sleep behavior disorderneurodegenerative disease association, evolving concepts, controversies, and future directions," Annals of the New York Academy of Sciences, vol. 1184, pp. 15-54, 2010.

[111] D. O. Claassen, K. A. Josephs, J. E. Ahlskog, M. H. Silber, M. Tippmann-Peikert, and B. F. Boeve, "REM sleep behavior disorder preceding other aspects of synucleinopathies by up to half a century," Neurology, vol. 75, no. 6, pp. 494-499, 2010.

[112] I. Arnulf, M. Ferraye, V. Fraix et al., "Sleep induced by stimulation in the human pedunculopontine nucleus area," Annals of Neurology, vol. 67, no. 4, pp. 546-549, 2010.

[113] A. Marques, K. Dujardin, M. Boucart et al., "REM sleep behaviour disorder and visuoperceptive dysfunction: a disorder of the ventral visual stream?" Journal of Neurology, vol. 257, no. 3, pp. 383-391, 2010.

[114] T. C. Thannickal, Y. Y. Lai, and J. M. Siegel, "Hypocretin (orexin) cell loss in Parkinson's disease," Brain, vol. 130, no. 6, pp. 1586-1595, 2007.

[115] R. Fronczek, S. Overeem, S. Y. Y. Lee et al., "Hypocretin (orexin) loss in Parkinson's disease," Brain, vol. 130, no. 6, pp. 1577-1585, 2007.

[116] Y. Compta, J. Santamaria, L. Ratti et al., "Cerebrospinal hypocretin, daytime sleepiness and sleep architecture in Parkinson's disease dementia," Brain, vol. 132, no. 12, pp. 3308-3317, 2009.

[117] H. Asai, M. Hirano, Y. Furiya et al., "Cerebrospinal fluidorexin levels and sleep attacks in four patients with Parkinson's disease," Clinical Neurology and Neurosurgery, vol. 111, no. 4, pp. 341-344, 2009.

[118] J. Kulisevsky, J. Pagonbarraga, B. Pascual-Sedano, C. GarcíaSánchez, and A. Gironell, "Prevalence and correlates of neuropsychiatric symptoms in Parkinson's disease without dementia," Movement Disorders, vol. 23, no. 13, pp. 18891896, 2008.

[119] I. Ferrer, "Early involvement of the cerebral cortex in Parkinson's disease: convergence of multiple metabolic defects," Progress in Neurobiology, vol. 88, no. 2, pp. 89-103, 2009.

[120] H. Braak, U. Rüb, E. N. H. Jansen Steur, K. Del Tredici, and R. A. I. De Vos, "Cognitive status correlates with neuropathologic stage in Parkinson disease," Neurology, vol. 64, no. 8, pp. 1404-1410, 2005.
[121] D. W. Dickson, H. Uchikado, H. Fujishiro, and Y. Tsuboi, "Evidence in favor of Braak staging of Parkinson's disease," Movement Disorders, vol. 25, supplement 1, pp. S78-82, 2010.

[122] P. M. Mattila, J. O. Rinne, H. Helenius, D. W. Dickson, and M. Röyttä, "Alpha-synuclein-immunoreactive cortical Lewy bodies are associated with cognitive impairment in Parkinson's disease," Acta Neuropathologica, vol. 100, no. 3, pp. 285-290, 2000.

[123] J. Molano, B. Boeve, T. Ferman et al., "Mild cognitive impairment associated with limbic and neocortical Lewy body disease: a clinicopathological study," Brain, vol. 133, no. 2, pp. 540-556, 2010.

[124] L. Parkkinen, T. Kauppinen, T. Pirttilä, J. M. Autere, and I. Alafuzoff, " $\alpha$-synuclein pathology does not predict extrapyramidal symptoms or dementia," Annals of Neurology, vol. 57, no. 1, pp. 82-91, 2005.

[125] L. Parkkinen, T. Pirttilä, M. Tervahauta, and I. Alafuzoff, "Widespread and abundant $\alpha$-synuclein pathology in a neurologically unimpaired subject," Neuropathology, vol. 25, no. 4, pp. 304-314, 2005.

[126] D. Weisman, M. Cho, C. Taylor, A. Adame, L. J. Thal, and L. A. Hansen, "In dementia with Lewy bodies, Braak stage determines phenotype, not Lewy body distribution," Neurology, vol. 69, no. 4, pp. 356-359, 2007.

[127] L. Parkkinen, T. Pirttilâ, and I. Alafuzoff, "Applicability of current staging/categorization of $\alpha$-synuclein pathology and their clinical relevance," Acta Neuropathologica, vol. 115, no. 4, pp. 399-407, 2008.

[128] R. E. Burke, W. T. Dauer, and J. P. G. Vonsattel, "A critical evaluation of the Braak staging scheme for Parkinson's disease," Annals of Neurology, vol. 64, no. 5, pp. 485-491, 2008.

[129] G. Halliday, M. Hely, W. Reid, and J. Morris, "The progression of pathology in longitudinally followed patients with Parkinson's disease," Acta Neuropathologica, vol. 115, no. 4, pp. 409-415, 2008.

[130] A. J. Harding, G. A. Broe, and G. M. Halliday, "Visual hallucinations in Lewy body disease relate to Lewy bodies in the temporal lobe," Brain, vol. 125, no. 2, pp. 391-403, 2002.

[131] R. Yamamoto, E. Iseki, N. Murayama et al., "Correlation in Lewy pathology between the claustrum and visual areas in brains of dementia with Lewy bodies," Neuroscience Letters, vol. 415, no. 3, pp. 219-224, 2007.

[132] M. E. Kalaitzakis, L. M. Christian, L. B. Moran, M. B. Graeber, R. K. B. Pearce, and S. M. Gentleman, "Dementia and visual hallucinations associated with limbic pathology in Parkinson's disease," Parkinsonism and Related Disorders, vol. 15, no. 3, pp. 196-204, 2009.

[133] G. Muntané, E. Dalfó, A. Martinez, and I. Ferrer, "Phosphorylation of tau and $\alpha$-synuclein in synaptic-enriched fractions of the frontal cortex in Alzheimer's disease, and in Parkinson's disease and related $\alpha$-synucleinopathies," Neuroscience, vol. 152, no. 4, pp. 913-923, 2008.

[134] W. J. Schulz-Schaeffer, "The synaptic pathology of $\alpha$ synuclein aggregation in dementia with Lewy bodies, Parkinson's disease and Parkinson's disease dementia," Acta Neuropathologica, vol. 120, pp. 131-143, 2010.

[135] K. Tanji, F. Mori, J. Mimura et al., "Proteinase K-resistant $\alpha$-synuclein is deposited in presynapses in human Lewy body disease and A53T $\alpha$-synuclein transgenic mice," Acta Neuropathologica, vol. 120, no. 2, pp. 145-154, 2010. 
[136] E. Dalfó, M. Barrachina, J. L. Rosa, S. Ambrosio, and I. Ferrer, "Abnormal $\alpha$-synuclein interactions with rab3a and rabphilin in diffuse Lewy body disease," Neurobiology of Disease, vol. 16, no. 1, pp. 92-97, 2004.

[137] E. Dalfó, J. L. Albasanz, M. Martín, and I. Ferrer, "Abnormal metabotropic glutamate receptor expression and signaling in the cerebral cortex in diffuse Lewy body disease is associated with irregular $\alpha$-synuclein/phospholipase C (PLC $\beta 1)$ interactions," Brain Pathology, vol. 14, no. 4, pp. 388-398, 2004.

[138] A. M. Owen, J. Doyon, A. Dagher, A. Sadikot, and A. C. Evans, "Abnormal basal ganglia outflow in Parkinson's disease identified with PET. Implications for higher cortical functions," Brain, vol. 121, no. 5, pp. 949-965, 1998.

[139] G. Dirnberger, C. D. Frith, and M. Jahanshahi, "Executive dysfunction in Parkinson's disease is associated with altered pallidal-frontal processing," NeuroImage, vol. 25, no. 2, pp. 588-599, 2005.

[140] R. Cools, E. Stefanova, R. A. Barker, T. W. Robbins, and A. M. Owen, "Dopaminergic modulation of high-level cognition in Parkinson's disease: the role of the prefrontal cortex revealed by PET," Brain, vol. 125, no. 3, pp. 584-594, 2002.

[141] O. Monchi, M. Petrides, B. Mejia-Constain, and A. P. Strafella, "Cortical activity in Parkinson's disease during executive processing depends on striatal involvement," Brain, vol. 130, no. 1, pp. 233-244, 2007.

[142] P. Marklund, A. Larsson, E. Elgh et al., “Temporal dynamics of basal ganglia under-recruitment in Parkinson's disease: transient caudate abnormalities during updating of working memory," Brain, vol. 132, no. 2, pp. 336-346, 2009.

[143] R. Y. Moore, A. L. Whone, and D. J. Brooks, "Extrastriatal monoamine neuron function in Parkinson's disease: an 18Fdopa PET study," Neurobiology of Disease, vol. 29, no. 3, pp. 381-390, 2008.

[144] V. L. Cropley, M. Fujita, W. Bara-Jimenez et al., "Preand post-synaptic dopamine imaging and its relation with frontostriatal cognitive function in Parkinson disease: PET studies with [11C]NNC 112 and [F]FDOPA," Psychiatry Research, vol. 163, no. 2, pp. 171-182, 2008.

[145] N. Sawamoto, P. Piccini, G. Hotton, N. Pavese, K. Thielemans, and D. J. Brooks, "Cognitive deficits and striato-frontal dopamine release in Parkinson's disease," Brain, vol. 131, no. 5, pp. 1294-1302, 2008.

[146] C. Zarow, S. A. Lyness, J. A. Mortimer, and H. C. Chui, "Neuronal loss is greater in the locus coeruleus than nucleus basalis and substantia nigra in Alzheimer and Parkinson diseases," Archives of Neurology, vol. 60, no. 3, pp. 337-341, 2003.

[147] J. L. W. Bosboom, D. Stoffers, and E. CH. Wolters, "The role of acetylcholine and dopamine in dementia and psychosis in Parkinson's disease," Journal of Neural Transmission, Supplement, no. 65, pp. 185-195, 2003.

[148] R. Hilker, A. V. Thomas, J. C. Klein et al., "Dementia in Parkinson disease: functional imaging of cholinergic and dopaminergic pathways," Neurology, vol. 65, no. 11, pp. 1716-1722, 2005.

[149] S. J. Baloyannis, V. Costa, and I. S. Baloyannis, "Morphological alterations of the synapses in the locus coeruleus in Parkinson's disease," Journal of the Neurological Sciences, vol. 248, no. 1-2, pp. 35-41, 2006.

[150] B. Dubois, B. Pillon, F. Lhermitte, and Y. Agid, "Cholinergic deficiency and frontal dysfunction in Parkinson's disease," Annals of Neurology, vol. 28, no. 2, pp. 117-121, 1990.
[151] P. Calabresi, B. Picconi, L. Parnetti, and M. Di Filippo, "A convergent model for cognitive dysfunctions in Parkinson's disease: the critical dopamine-acetylcholine synaptic balance," Lancet Neurology, vol. 5, no. 11, pp. 974-983, 2006.

[152] H. Shimada, S. Hirano, H. Shinotoh et al., "Mapping of brain acetylcholinesterase alterations in Lewy body disease by PET," Neurology, vol. 73, no. 4, pp. 273-278, 2009.

[153] N. I. Bohnen and R. L. Albin, "Cholinergic denervation occurs early in Parkinson disease," Neurology, vol. 73, no. 4, pp. 256-257, 2009.

[154] N. I. Bohnen and R. L. Albin, "The cholinergic systemand Parkinson disease," Behavioural Brain Research. In press.

[155] F. Roselli, N. M. Pisciotta, M. Pennelli et al., "Midbrain SERT in degenerative parkinsonisms: a 123I-FP-CIT SPECT study," Movement Disorders, vol. 25, no. 12, pp. 1853-1859, 2010.

[156] S. W. Yong, J. K. Yoon, Y. S. An, and P. H. Lee, "A comparison of cerebral glucose metabolism in Parkinson's disease, Parkinson's disease dementia and dementia with Lewy bodies," European Journal of Neurology, vol. 14, no. 12, pp. 1357-1362, 2007.

[157] A. Wallin, S. Ekberg, K. Lind, V. Milos, A.-K. Granérus, and G. Granerus, "Posterior cortical brain dysfunction in cognitively impaired patients with Parkinson's disease-a rCBF scintigraphy study," Acta Neurologica Scandinavica, vol. 116, no. 6, pp. 347-354, 2007.

[158] C. Huang, C. Tang, A. Feigin et al., "Changes in network activity with the progression of Parkinson's disease," Brain, vol. 130, no. 7, pp. 1834-1846, 2007.

[159] C. Huang, P. Mattis, K. Perrine, N. Brown, V. Dhawan, and D. Eidelberg, "Metabolic abnormalities associated with mild cognitive impairment in Parkinson disease," Neurology, vol. 70, no. 16, pp. 1470-1477, 2008.

[160] C. Tessa, M. Giannelli, R. Della Nave et al., "A whole-brain analysis in de novo Parkinson disease," American Journal of Neuroradiology, vol. 29, no. 4, pp. 674-680, 2008.

[161] A. T. Karagulle Kendi, S. Lehericy, M. Luciana, K. Ugurbil, and P. Tuite, "Altered diffusion in the frontal lobe in Parkinson disease," American Journal of Neuroradiology, vol. 29, no. 3, pp. 501-505, 2008.

[162] S.-J. Lee, J.-S. Kim, J.-Y. Yoo et al., "Influence of white matter hyperintensities on the cognition of patients with parkinson disease," Alzheimer Disease and Associated Disorders, vol. 24, no. 3, pp. 227-233, 2010.

[163] K. A. Jellinger, "Prevalence and impact of cerebrovascular lesions in Alzheimer and Lewy body diseases," Neurodegenerative Diseases, vol. 7, no. 1-3, pp. 112-115, 2010.

[164] A. H. Schapira, "Mitochondria in the aetiology and pathogenesis of Parkinson's disease," The Lancet Neurology, vol. 7, no. 1, pp. 97-109, 2008.

[165] G. H. Sack, "Mitochondrial matters in Parkinson disease: introduction," Journal of Bioenergetics and Biomembranes, vol. 41, no. 6, pp. 465-467, 2009.

[166] K. F. Winklhofer and C. Haass, "Mitochondrial dysfunction in Parkinson's disease," Biochimica et Biophysica Acta, vol. 1802, no. 1, pp. 29-44, 2010.

[167] P. M. Abou-Sleiman, M. M. K. Muqit, and N. W. Wood, "Expanding insights of mitochondrial dysfunction in Parkinson's disease," Nature Reviews Neuroscience, vol. 7, no. 3, pp. 207-219, 2006.

[168] Y. Yang, S. Gehrke, MD. E. Haque et al., "Inactivation of Drosophila DJ-1 leads to impairments of oxidative stress response and phosphatidylinositol 3-kinase/Akt signaling," Proceedings of the National Academy of Sciences of the United States of America, vol. 102, no. 38, pp. 13670-13675, 2005. 
[169] R. Ved, S. Saha, B. Westlund et al., "Similar patterns of mitochondrial vulnerability and rescue induced by genetic modification of $\alpha$-synuclein, parkin, and DJ-1 in Caenorhabditis elegans," Journal of Biological Chemistry, vol. 280, no. 52, pp. 42655-42668, 2005.

[170] L. Silvestri, V. Caputo, E. Bellacchio et al., "Mitochondrial import and enzymatic activity of PINK1 mutants associated to recessive parkinsonism," Human Molecular Genetics, vol. 14, no. 22, pp. 3477-3492, 2005.

[171] J. Park, S. B. Lee, S. Lee et al., "Mitochondrial dysfunction in Drosophila PINK1 mutants is complemented by parkin," Nature, vol. 441, no. 7097, pp. 1157-1161, 2006.

[172] I. E. Clark, M. W. Dodson, C. Jiang et al., "Drosophila pink1 is required for mitochondrial function and interacts genetically with parkin," Nature, vol. 441, no. 7097, pp. 11621166, 2006.

[173] A. C. Poole, R. E. Thomas, L. A. Andrews, H. M. McBride, A. J. Whitworth, and L. J. Pallanck, "The PINK1/Parkin pathway regulates mitochondrial morphology," Proceedings of the National Academy of Sciences of the United States of America, vol. 105, no. 5, pp. 1638-1643, 2008.

[174] W. W. Smith, Z. Pei, H. Jiang et al., "Leucine-rich repeat kinase 2 (LRRK2) interacts with parkin, and mutant LRRK2 induces neuronal degeneration," Proceedings of the National Academy of Sciences of the United States of America, vol. 102, no. 51, pp. 18676-18681, 2005.

[175] Y. Suzuki, Y. Imai, H. Nakayama, K. Takahashi, K. Takio, and R. Takahashi, "A serine protease, HtrA2, is released from the mitochondria and interacts with XIAP, inducing cell death," Molecular Cell, vol. 8, no. 3, pp. 613-621, 2001.

[176] M. W. Dodson and M. Guo, "Pink1, Parkin, DJ-1 and mitochondrial dysfunction in Parkinson's disease," Current Opinion in Neurobiology, vol. 17, no. 3, pp. 331-337, 2007.

[177] R. K. Dagda and C. T. Chu, "Mitochondrial quality control: insights on how Parkinson's disease related genes PINK1, parkin, and Omi/HtrA2 interact to maintain mitochondrial homeostasis," Journal of Bioenergetics and Biomembranes, vol. 41, no. 6, pp. 473-479, 2009.

[178] M. Jendrach, S. Gispert, F. Ricciardi, M. Klinkenberg, R. Schemm, and G. Auburger, "The mitochondrial kinase PINK1, stress response and Parkinson's disease," Journal of Bioenergetics and Biomembranes, vol. 41, no. 6, pp. 481-486, 2009.

[179] A. J. Whitworth and L. J. Pallanck, "The PINK1/Parkin pathway: a mitochondrial quality control system?” Journal of Bioenergetics and Biomembranes, vol. 41, no. 6, pp. 499-503, 2009.

[180] S. Papa, A. M. Sardanelli, N. Capitanio, and C. Piccoli, "Mitochondrial respiratory dysfunction and mutations in mitochondrial DNA in PINK1 familial Parkinsonism," Journal of Bioenergetics and Biomembranes, vol. 41, no. 6, pp. 509516, 2009.

[181] A. Navarro, A. Boveris, M. J. Bández et al., "Human brain cortex: mitochondrial oxidative damage and adaptive response in Parkinson disease and in dementia with Lewy bodies," Free Radical Biology and Medicine, vol. 46, no. 12, pp. 1574-1580, 2009.

[182] A. Navarro and A. Boveris, "Brain mitochondrial dysfunction and oxidative damage in Parkinson's disease," Journal of Bioenergetics and Biomembranes, vol. 41, no. 6, pp. 517-521, 2009.

[183] P. M. Keeney, J. Xie, R. A. Capaldi, and J. P. Bennett, "Parkinson's disease brain mitochondrial complex I has oxidatively damaged subunits and is functionally impaired and misassembled," Journal of Neuroscience, vol. 26, no. 19, pp. 5256-5264, 2006.

[184] E. Hattingen, J. Magerkurth, U. Pilatus et al., "Phosphorus and proton magnetic resonance spectroscopy demonstrates mitochondrial dysfunction in early and advanced Parkinson's disease," Brain, vol. 132, no. 12, pp. 3285-3297, 2009.

[185] Z. I. Alam, S. E. Daniel, A. J. Lees, D. C. Marsden, P. Jenner, and B. Halliwell, "A generalised increase in protein carbonyls in the brain in Parkinson's but not incidental Lewy body disease," Journal of Neurochemistry, vol. 69, no. 3, pp. 13261329, 1997.

[186] E. Dalfó, M. Portero-Otín, V. Ayala, A. Martínez, R. Pamplona, and I. Ferrer, "Evidence of oxidative stress in the neocortex in incidental Lewy body disease," Journal of Neuropathology and Experimental Neurology, vol. 64, no. 9, pp. 816-830, 2005.

[187] E. Dalfó and I. Ferrer, "Early $\alpha$-synuclein lipoxidation in neocortex in Lewy body diseases," Neurobiology of Aging, vol. 29, no. 3, pp. 408-417, 2008.

[188] J. Choi, A. I. Levey, S. T. Weintraub et al., "Oxidative Modifications and Down-regulation of Ubiquitin Carboxylterminal Hydrolase L1 Associated with Idiopathic Parkinson's and Alzheimer's Diseases," Journal of Biological Chemistry, vol. 279, no. 13, pp. 13256-13264, 2004.

[189] J. Choi, H. D. Rees, S. T. Weintraub, A. I. Levey, L. S. Chin, and L. Li, "Oxidative modifications and aggregation of $\mathrm{Cu}, \mathrm{Zn}$-superoxide dismutase associated with alzheimer and Parkinson diseases," Journal of Biological Chemistry, vol. 280, no. 12, pp. 11648-11655, 2005.

[190] J. Choi, M. C. Sullards, J. A. Olzmann et al., "Oxidative damage of DJ-1 is linked to sporadic Parkinson and Alzheimer diseases," Journal of Biological Chemistry, vol. 281, no. 16, pp. 10816-10824, 2006.

[191] A. Gómez and I. Ferrer, "Increased oxidation of certain glycolysis and energy metabolism enzymes in the frontal cortex in Lewy body diseases," Journal of Neuroscience Research, vol. 87, no. 4, pp. 1002-1013, 2009.

[192] J. H. T. Power and P. C. Blumbergs, "Cellular glutathione peroxidase in human brain: cellular distribution, and its potential role in the degradation of Lewy bodies in Parkinson's disease and dementia with Lewy bodies," Acta Neuropathologica, vol. 117, no. 1, pp. 63-73, 2009.

[193] C. C. Tang, K. L. Poston, V. Dhawan, and D. Eidelberg, "Abnormalities in metabolic network activity precede the onset of motor symptoms in Parkinson's disease," Journal of Neuroscience, vol. 30, no. 3, pp. 1049-1056, 2010.

[194] N. Fabelo, V. Martín, G. Santpere et al., "Severe alterations in lipid composition of frontal cortex lipid rafts from Parkinson's disease and incidental Parkinson's disease," submitted.

[195] I. Ferrer, "Altered mitochondria, energy metabolism, voltagedependent anion channel, and lipid rafts converge to exhaust neurons in Alzheimer's disease," Journal of Bioenergetics and Biomembranes, vol. 41, no. 5, pp. 425-431, 2009.

[196] A. Gomez and I. Ferrer, "Involvement of the cerebral cortex in Parkinson disease linked with G2019S LRRK2 mutation without cognitive impairment," Acta Neuropathologica, vol. 20, pp. 155-167, 2010.

[197] A. McKinlay, R. C. Grace, J. C. Dalrymple-Alford, and D. Roger, "Cognitive characteristics associated with mild cognitive impairment in parkinson's disease," Dementia and Geriatric Cognitive Disorders, vol. 28, no. 2, pp. 121-129, 2009. 
[198] K. F. Pedersen, G. Alves, D. Aarsland, and J. P. Larsen, "Occurrence and risk factors for apathy in Parkinson disease: a 4-year prospective longitudinal study," Journal of Neurology, Neurosurgery and Psychiatry, vol. 80, no. 11, pp. 1279-1282, 2009.

[199] J. R. Sanchez-Ramos, R. Ortoll, and G. W. Paulson, "Visual hallucinations associated with Parkinson disease," Archives of Neurology, vol. 53, no. 12, pp. 1265-1268, 1996.

[200] R. Inzelberg, S. Kipervasser, and A. D. Korczyn, "Auditory hallucinations in Parkinson's disease," Journal of Neurology Neurosurgery and Psychiatry, vol. 64, no. 4, pp. 533-535, 1998.

[201] E. CH. Wolters, "Intrinsic and extrinsic psychosis in Parkinson's disease," Journal of Neurology, Supplement, vol. 248, supplement 3, pp. III22-III27, 2001.

[202] A. D. de Maindreville, G. Fénelon, and F. Mahieux, "Hallucinations in Parkinson's disease: a follow-up study," Movement Disorders, vol. 20, no. 2, pp. 212-217, 2005.

[203] S. Papapetropoulos and D. C. Mash, "Psychotic symptoms in Parkinson's disease: from description to etiology," Journal of Neurology, vol. 252, no. 7, pp. 753-764, 2005.

[204] W. Birkmayer and P. Riederer, "Responsibility of extrastriatal areas for the appearance of psychotic symptoms. (Clinical and biochemical human post mortem findings)," Journal of Neural Transmission, vol. 37, no. 2, pp. 175-182, 1975.

[205] R. Mayeux, Y. Stern, and J. B.W. Williams, "Clinical and biochemical features of depression in Parkinson's disease," American Journal of Psychiatry, vol. 143, no. 6, pp. 756-759, 1986.

[206] E. K. Perry, I. McKeith, P. Thompson et al., "Topography, extent, and clinical relevance of neurochemical deficits in dementia of Lewy body type, Parkinson's disease, and Alzheimer's disease," Annals of the New York Academy of Sciences, vol. 640, pp. 197-202, 1991.

[207] P. Remy, M. Doder, A. Lees, N. Turjanski, and D. Brooks, "Depression in Parkinson's disease: loss of dopamine and noradrenaline innervation in the limbic system," Brain, vol. 128, no. 6, pp. 1314-1322, 2005.

[208] P. G. Frisina, V. Haroutunian, and L. S. Libow, "The neuropathological basis for depression in Parkinson's disease," Parkinsonism and Related Disorders, vol. 15, no. 2, pp. 144$148,2009$.

[209] J. A. Parkinson, T. W. Robbins, and B. J. Everitt, "Dissociable roles of the central and basolateral amygdala in appetitive emotional learning," European Journal of Neuroscience, vol. 12, no. 1, pp. 405-413, 2000.

[210] B. J. Everitt, R. N. Cardinal, J. A. Parkinson, and T. W. Robbins, "Appetitive behavior: impact of amygdala-dependent mechanisms of emotional learning," Annals of the New York Academy of Sciences, vol. 985, pp. 233-250, 2003.

[211] Y. Kan, M. Kawamura, Y. Hasegawa, S. Mochizuki, and K. Nakamura, "Recognition of emotion from facial, prosodic and written verbal stimuli in Parkinson's disease," Cortex, vol. 38, no. 4, pp. 623-630, 2002.

[212] N. Yoshimura, M. Kawamura, Y. Masaoka, and I. Homma, "The amygdala of patients with Parkinson's disease is silent in response to fearful facial expressions," Neuroscience, vol. 131, no. 2, pp. 523-534, 2005.

[213] N. Ibarretxe-Bilbao, C. Junque, E. Tolosa et al., "Neuroanatomical correlates of impaired decision-making and facial emotion recognition in early Parkinson's disease," European Journal of Neuroscience, vol. 30, no. 6, pp. 11621171, 2009.
[214] P. Delaveau, P. Salgado-Pineda, T. Witjas et al., "Dopaminergic modulation of amygdala activity during emotion recognition in patients with parkinson disease," Journal of Clinical Psychopharmacology, vol. 29, no. 6, pp. 548-554, 2009. 


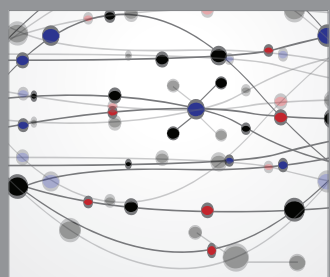

The Scientific World Journal
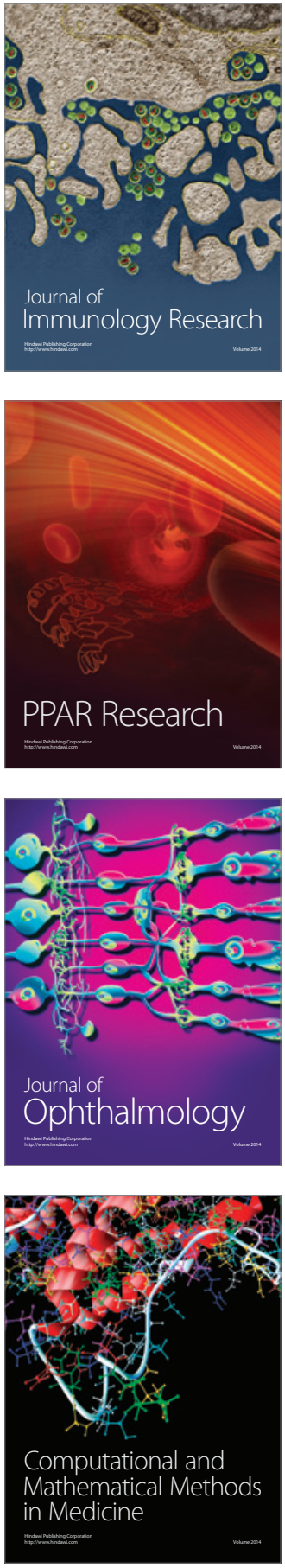

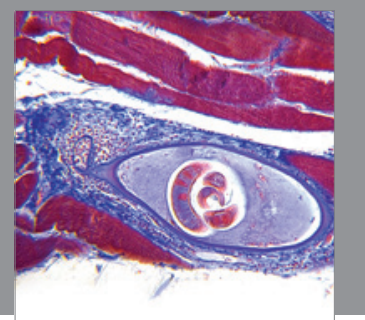

Gastroenterology

Research and Practice
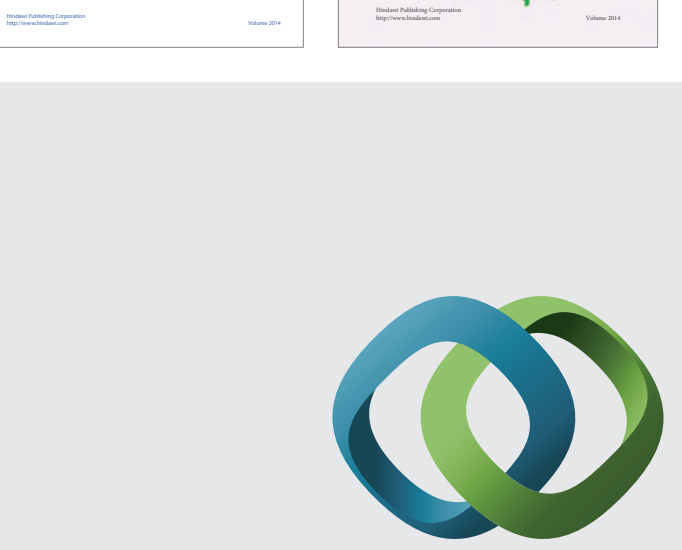

\section{Hindawi}

Submit your manuscripts at

http://www.hindawi.com
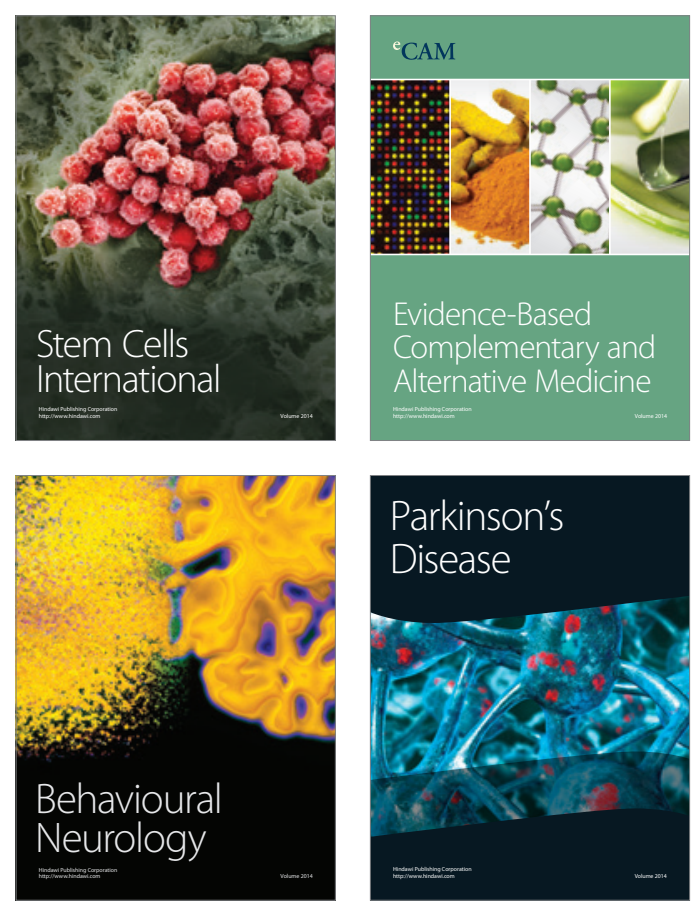

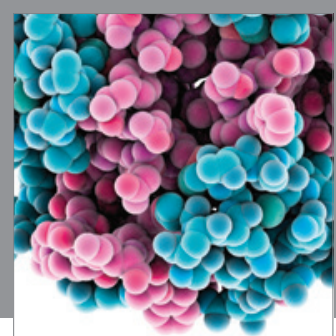

Journal of
Diabetes Research

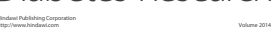

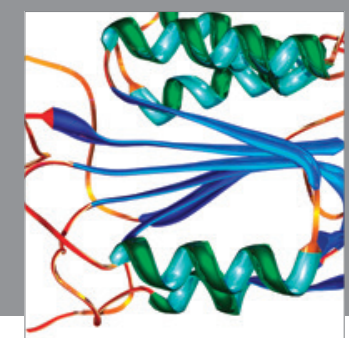

Disease Markers
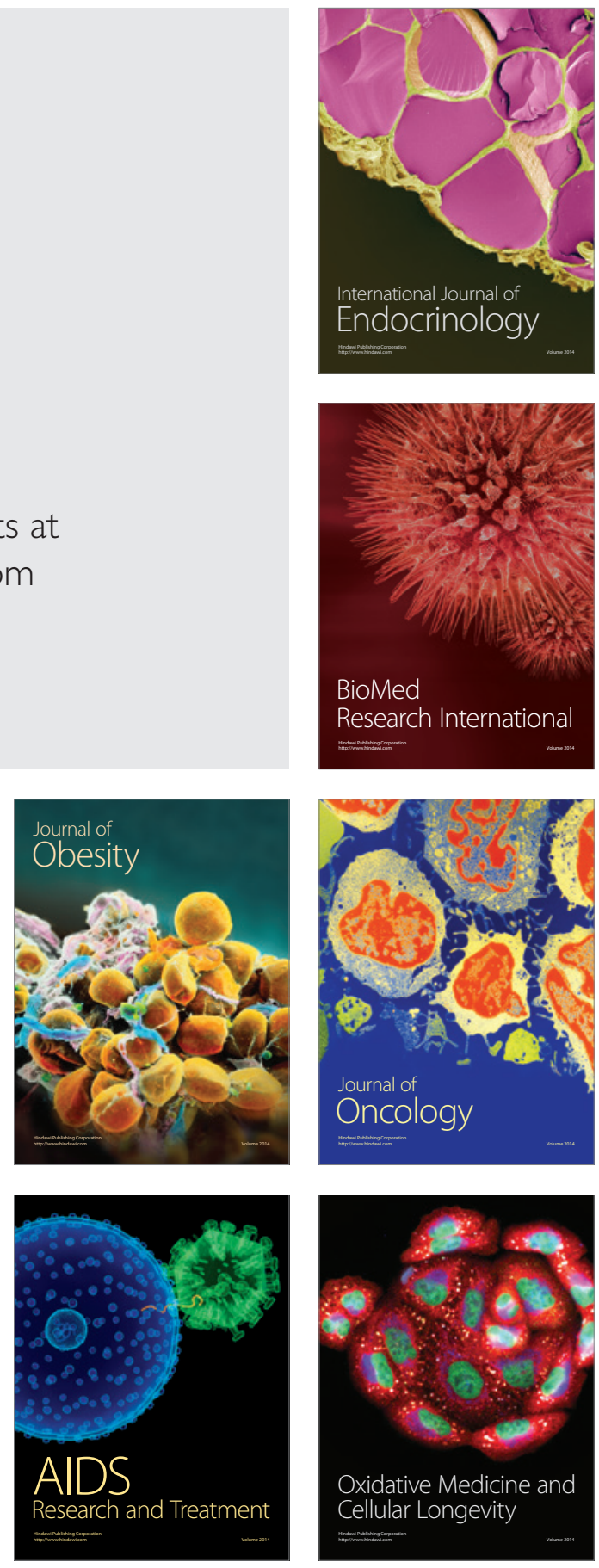